\title{
,asu \\ APOE Polymorphism and Endocrine Functions in Subjects with Morbid Obesity Undergoing Bariatric Surgery
}

\author{
Per G. Farup ${ }^{1,2, *(\mathcal{C}, \text { Aina Jansen }}{ }^{3}$, Knut Hestad ${ }^{1,4}$, Jan O. Aaseth $^{1,4}$ and Helge Rootwelt ${ }^{5}$ \\ 1 Department of Research, Innlandet Hospital Trust, PB 104, N-2381 Brumunddal, Norway; \\ knut.hestad@inn.no (K.H.); Jan.Aaseth@inn.no (J.O.A.) \\ 2 Department of Clinical and Molecular Medicine, Faculty of Medicine and Health Sciences, Norwegian \\ University of Science and Technology, N-7491 Trondheim, Norway \\ 3 Department of Surgery, Innlandet Hospital Trust, N-2819 Gjøvik, Norway; \\ Aina.Jansen@sykehuset-innlandet.no \\ 4 Department of Health and Nursing Science, Faculty of Health and Social Sciences, \\ Inland Norway University of Applied Sciences, N-2418 Elverum, Norway \\ 5 Department of Medical Biochemistry, Oslo University Hospital, N-0424 Oslo, Norway; hrootwel@ous-hf.no \\ * Correspondence: per.farup@ntnu.no; Tel.: +47-94818603
}

check for updates

Citation: Farup, P.G.; Jansen, A.; Hestad, K.; Aaseth, J.O.; Rootwelt, H. $A P O E$ Polymorphism and Endocrine Functions in Subjects with Morbid Obesity Undergoing Bariatric Surgery. Genes 2022, 13, 222. https:// doi.org/10.3390/genes13020222

Academic Editors: Katarina Trebušak Podkrajšek and Primož Kotnik

Received: 15 December 2021

Accepted: 23 January 2022

Published: 25 January 2022

Publisher's Note: MDPI stays neutral with regard to jurisdictional claims in published maps and institutional affiliations.

Copyright: (C) 2022 by the authors. Licensee MDPI, Basel, Switzerland. This article is an open access article distributed under the terms and conditions of the Creative Commons Attribution (CC BY) license (https:// creativecommons.org/licenses/by/ $4.0 /)$.

\begin{abstract}
Background: Obesity is an interplay between genes and the environment, including lifestyle. The genetics of obesity is insufficiently understood. Apolipoprotein E (APOE) genetic polymorphism has been associated with a wide range of disorders. Knowing that some APOE alleles are associated with obesity and endocrine disorders that are common in obesity, the present study aimed at exploring associations between $A P O E$ polymorphisms and endocrine functions in subjects with obesity undergoing bariatric surgery. Methods: Analyses of hormones in blood collected before and one year after bariatric surgery were examined. The APOE alleles were grouped as follows: $\mathrm{E} 2=\varepsilon 2 \varepsilon 2+\varepsilon 2 \varepsilon 3 ; \mathrm{E} 3=\varepsilon 3 \varepsilon 3+\varepsilon 2 \varepsilon 4 ; \mathrm{E} 4=\varepsilon 3 \varepsilon 4+\varepsilon 4 \varepsilon 4$. The APOE groups were analysed as nominal and ordered groups (E2-E3-E4) with a linear mixed model to predict the hormonal effects of the groups. Results: Forty-nine women (79\%) and thirteen (21\%) men with a mean age of 47.7 (SD 8.5) years were included in the study. The adiponectin level was significantly lower $(p<0.05)$ in the E2 group compared with the E4 group. Adiponectin and cortisol were positively and negatively associated, respectively, with the ordered APOE groups. Conclusions: The ordered APOE groups E2-E3-E4 were significantly associated with high and low levels of adiponectin and cortisol, respectively. The findings indicate $A P O E$-mediated effects on body weight and metabolic functions in subjects with morbid obesity.
\end{abstract}

Keywords: $A P O E$ polymorphism; endocrine function; obesity; bariatric surgery

\section{Introduction}

The cause of obesity and overweight is an energy imbalance between calories consumed and expended [1]. Lifestyle factors such as unfavourable dietary habits, a sedentary lifestyle and psycho-social factors are most important, but endocrine disorders and genetic predisposition also have an identifiable contribution to obesity [2].

Ghrelin and the adipokines leptin and adiponectin have appetite-regulating effects [3]. Adiponectin is a metabolic health product of the adipose tissue and exerts appetiteregulating effects [4]. Leptin is released from adipose tissue and regulates appetite and energy homeostasis [5]. Leptin deficiency is a primary cause of obesity [2,5]. Leptin and ghrelin, together with other hormones, regulate hunger and satiety $[3,6]$.

Endocrine disorders are common in subjects with obesity. Cushing's syndrome, growth hormone deficiency, hypothyroidism and pseudohypoparathyroidism are associated with obesity and are secondary causes of obesity [2]. Sex hormones are influenced by obesity, both in men and women, and tend to normalise after bariatric surgery $[7,8]$. 
Obesity is an interplay between genes, epigenetics and the environment, including lifestyle [9]. Genes' regulation of obesity is either monogenic or polygenic and is often poorly understood. Apolipoprotein $\mathrm{E}(A P O E)$ genetic polymorphism has been associated with a wide range of disorders. A recently published study reported associations with 37 outcomes representing 18 distinct disorders [10]. APOE $\varepsilon 4 \varepsilon 4$ was associated with a reduced prevalence of obesity $(\mathrm{OR}=0.78)$, and $\varepsilon 2 \varepsilon 2$ with an increased prevalence of obesity $(\mathrm{OR}=1.22)$ compared with $\varepsilon 3 \varepsilon 3$. Apolipoprotein E could be the link between APOE genetic polymorphism and obesity. The conventional conception has been that apolipoprotein E promotes obesity by the increase in lipid to white adipose tissue. More recently, apolipoprotein E3 in the brain has been associated with fat accumulation and obesity, and hepatically expressed apolipoprotein E3 has the opposite effect [11]. In a previous study, we demonstrated an association between the presence of the allele $\varepsilon 2$ and improvement in all psychosomatic disorders, and positive and negative associations between c-reactive protein (CRP) and the alleles $\varepsilon 2$ and $\varepsilon 4$, respectively [12].

Knowing that some $A P O E$ alleles are associated with obesity and that endocrine disorders are common in subjects with obesity, the present study aimed to explore associations between $A P O E$ polymorphism and endocrine functions in subjects with obesity undergoing bariatric surgery.

\section{Materials and Methods}

\subsection{Study Design and Participants}

This retrospective cohort study used data from the prospective cohort study MO-BiPS (Morbid Obesity-BioPsychoSocial impacts). The data are subsets of data used for other purposes in previously published papers $[12,13]$

Subjects with morbid obesity, defined as BMI $>40 \mathrm{~kg} / \mathrm{m}^{2}$ or BMI $>35 \mathrm{~kg} / \mathrm{m}^{2}$ with obesity-related complications and referred to the obesity unit at Innlandet Hospital Trust, Gjøvik, Norway for evaluation of bariatric surgery, were available for inclusion. Subjects with present or previous somatic or psychiatric disorders or drug or alcohol abuse were excluded at the doctors' discretion.

In the first six months after inclusion, the participants went through a behavioural weight loss intervention with three separate one-hour-long individual consultations and seven weekly group meetings with information about the operation, dietary recommendations and physical activity advice. During the last three weeks prior to bariatric surgery, they followed a strict "crispbread diet" or an alternative powder diet, both with a maximum of $4200 \mathrm{~kJ}$ [14]. Bariatric surgery was performed as a standard Roux-en-Y gastric bypass or gastric sleeve procedure at the surgeons' discretion $[15,16]$. There were regular follow-up visits after surgery.

Data from the visits immediately before surgery and the follow-up visit one year later were used in this study. Participants with complete datasets from these visits were included in the analyses.

\subsection{Variables}

This study used the following data from the prospective MO-BiPS cohort study:

- Demographic and anthropometric data: age (years), gender (male/female), height (m), body weight $(\mathrm{kg})$ and body mass index (BMI; $\left.\mathrm{kg} / \mathrm{m}^{2}\right)$;

- Blood tests (reference values are given for the age and BMI of the study population);

- Thyroid Stimulating Hormone (TSH); reference values women/men: 0.5-3.6/ 0.27-4.2 mIE/L;

- $\quad$ Free Thyroxin (fT4); reference values women/men: 8.0-21/12-22 pmol/L;

- $\quad$ Free Triiodothyronine (fT3); reference values women/men: 2.8-7.0/2.7-6.3 pmol/L;

- Reverse Triiodothyronine (rT3); reference values women/men: 0.23-0.54/0.14-0.54 pmol/L;

- $\quad$ Parathyroid hormone (PTH); reference values 1.5-7.0 pmol/L;

- Cortisol; reference morning values: 138-690 nmol/L; 
- Sex Hormone Binding Globulin (SHBG); reference values women/men: 23-100/ 8-60 nmol/L;

- Testosterone; reference values: women $<50$ years of age: $\leq 1.9 ; \geq 50$ years of age: $\leq 1.1 \mathrm{nmol} / \mathrm{L}$, men $20-40$ years: $7.2-24 ; \geq 40$ years: $4.6-24 \mathrm{nmol} / \mathrm{L}$;

- Free Testosterone Index $(\mathrm{FTI})($ testosterone $(\mathrm{nmol} / \mathrm{L}) \times 10 / \mathrm{SHBG}(\mathrm{nmol} / \mathrm{L}))$ : women 0.1-0.3; men age 20-39: 2.4-11.8; age 40-64: 1.5-7.3;

- $\mathrm{HbA1c}$; reference values $4.7-6.0 \%$.

Jansen et al. described the hormone analyses in detail [12].

- Leptin; reference values for BMI < 25: women/men: 80-2500/<950 pmol/L;

- Adiponectin; reference values women/men 4-22/2-20 mg/L;

- Ghrelin (acylated and non-acylated); reference values: 686-1731 pg/mL.

The adipokines were analysed at the Hormone Laboratory, Oslo University Hospital, Oslo, Norway (accredited by the Norwegian Accreditation according to the requirements of the NS-EN ISO/IEC 17,025 TEST 099) with competitive radioimmunoassay (RIA). Ghrelin, leptin and adiponectin were not included in the accreditation. The results were used in another context in a recently submitted paper by Jansen A. et. al.

- Genotyping. The APOE alleles were determined. There is no consensus regarding the grouping and order of the $A P O E$ variants. In particular, grouping of the $\varepsilon 2 \varepsilon 4$ is difficult. The following order of the APOE variants was chosen: $\varepsilon 2 \varepsilon 2, \varepsilon 2 \varepsilon 3, \varepsilon 3 \varepsilon 3, \varepsilon 2 \varepsilon 4$, $\varepsilon 3 \varepsilon 4$, e4 $\varepsilon 4$, which is in accordance with other papers, e.g., the comprehensive review by Lumsden et al. [10]. Based on the order of the APOE variants and because some groups were small (the smallest one was $\varepsilon 2 \varepsilon 4$ with one participant), we combined the genetic variants into three groups: E2 $(\varepsilon 2 \varepsilon 2+\varepsilon 2 \varepsilon 3), \mathrm{E} 3(\varepsilon 3 \varepsilon 3+\varepsilon 2 \varepsilon 4)$ and E4 $(\varepsilon 3 \varepsilon 4+\varepsilon 4 \varepsilon 4)$ according to Han et al. [17]. This is in accordance with the observation that for many clinical or biochemical properties investigated and published [10,12,17], the $\varepsilon 2$ and $\varepsilon 4$ alleles have opposite effects relative to the $\varepsilon 3$ allele. Therefore, it makes sense in a clinical setting to group $\varepsilon 2 \varepsilon 4$ alleles phenotypically as E3 although the $\varepsilon 2 \varepsilon 4$ genotype is not genetically $\varepsilon 3$.

Genotyping was performed at the Department of Medical Biochemistry, Oslo University Hospital-Rikshospitalet, Oslo, Norway using real-time polymerase chain reactions, described by Hestad et al. [18].

\subsection{Statistical Analyses}

Descriptive data are reported as mean (SD) and number with proportion (\%). Values before and after surgery were compared using a paired $t$-test. A linear mixed regression model for repeated measurements was used to analyse predictors of the hormones, and the results were reported as the estimate (B-value) with $95 \%$ confidence interval and $p$-values. The APOE groups E2, E3 and E4 were analysed as nominal groups with comparisons between the groups one-to-one and as an ordered variable with rank order: E2-E3-E4. $p$-values $<0.05$ were judged as statistically significant. The normality of the residuals of the mixed model linear regression was confirmed by the visual inspection of QQ-plots. The analyses were performed with IBM SPSS Statistics for Windows, version 27.0 (IBM Corp., Armonk, NY, USA). The $p$-values were adjusted for multiple testing ad modum Benjamini-Hochberg with R-Studio version 1.4.1106 and reported as q-values. Because the results showed associations between adiponectin and the APOE genetic variants, $\mathrm{HbA1c}$ was added post hoc as a dependent variable.

\section{Results}

One hundred and forty-two subjects were included in the main study, twenty-one withdrew during the behavioural intervention and one hundred and twenty-one underwent bariatric surgery. Sixty-two participants who had complete data before and 12 months after surgery were included in this study. Table 1 gives the patient characteristics. 
There was a significant difference in adiponectin between the groups E2 and E4, differences in $\mathrm{HbA} 1 \mathrm{c}$ (post hoc analyses) between E2 and E3 and differences between E3 and $\mathrm{E} 4$ adjusted for age, gender, BMI and point of time. No significant associations were detected after adjusting for multiple testing. Table 2 gives all associations between the hormones and the APOE groups.

Table 3 gives the associations between the ordered E groups (order E2-E3-E4) and the hormones. Adiponectin and cortisol were positively and negatively associated with the ordered E groups. No significant associations were detected after adjusting for multiple testing.

Figure 1 shows the two significant associations in Table 3 between the APOE groups and the hormones presented as the regression lines adjusted for the mean of the other variables.

Table 1. Patient characteristics. For gender-dependent variables, values are given for men and women.

\begin{tabular}{|c|c|c|c|}
\hline & Before Surgery & After Surgery & $\begin{array}{l}\text { Statistics } \\
p \text {-Values }\end{array}$ \\
\hline Male/female & $13(21 \%) / 49(79 \%)$ & - & - \\
\hline Age (years) & $44.7(8.5)$ & - & - \\
\hline $\begin{array}{c}\text { Type of surgery } \\
\text { R-Y Gastric bypass/Sleeve }\end{array}$ & $52(84 \%) / 10(16 \%)$ & - & - \\
\hline $\begin{array}{c}A P O E \text { groups } \varepsilon 2 \varepsilon 3 / \varepsilon 3 \varepsilon 3 / \varepsilon 2 \varepsilon 4 / \\
\varepsilon 3 \varepsilon 4 / \varepsilon 4 \varepsilon 4\end{array}$ & $\begin{array}{c}7(11 \%) / 31(50 \%) / 1(2 \%) / \\
21(34 \%) / 2(3 \%)\end{array}$ & & \\
\hline $\mathrm{BMI}\left(\mathrm{kg} / \mathrm{m}^{2}\right)$ & $39.0(3.2)$ & $28.2(3.6)$ & $<0.001$ \\
\hline TSH (mIE/L) & $1.71(1.39)$ & $1.66(0.98)$ & 0.764 \\
\hline Thyroxin (T4) (pmol/L) & $16.8(3.5)$ & $15.9(3.9)$ & 0.089 \\
\hline Free T3 $(\mathrm{pmol} / \mathrm{L})$ & $4.58(0.76)$ & $4.59(1.12)$ & 0.959 \\
\hline Reverse T3 (pmol/L) & $0.51(0.20)$ & $0.41(0.17)$ & $<0.001$ \\
\hline Parathyroid hormon (pmol/L) & $5.51(2.19)$ & $5.61(1.77)$ & 0.721 \\
\hline Cortisol (nmol/L) & $296(86)$ & $358(105)$ & $<0.001$ \\
\hline SHBG (nmol/L) & $49.3(29.8)$ & $82.4(42.2)$ & $<0.001$ \\
\hline Men & $31.5(12.4)$ & $56.15(28.4)$ & 0.002 \\
\hline Women & $54.1(31.3)$ & $89.4(42.8)$ & $<0.001$ \\
\hline Testosterone (nmol/L) & $3.2(5.5)$ & $4.9(8.9)$ & 0.001 \\
\hline Men & $12.6(5.7)$ & $20.4(8.5)$ & $<0.001$ \\
\hline Women & $0.7(0.3)$ & $0.8(0.4)$ & 0.294 \\
\hline Free testosterone index & $1.03(1.79)$ & $0.96(1.88)$ & 0.570 \\
\hline Men & $4.24(1.43)$ & $4.21(1.86)$ & 0.968 \\
\hline Women & $0.17(0.11)$ & $0.10(0.06)$ & $<0.001$ \\
\hline Leptin (pmol/L) & $2212(837)$ & 1107 (674) & $<0.001$ \\
\hline Men & $1370(459)$ & $529(433)$ & $<0.001$ \\
\hline Women & $2436(771)$ & $1260(644)$ & $<0.001$ \\
\hline Adiponectin (mg/L) & $7.7(4.2)$ & $13.1(7.0)$ & $<0.001$ \\
\hline Men & $4.4(1.8)$ & $10.8(5.2)$ & $<0.001$ \\
\hline Women & $8.6(4.2)$ & $13.7(7.4)$ & $<0.001$ \\
\hline Ghrelin (pg/mL) & $1108(369)$ & 1247 (615) & 0.025 \\
\hline R-Y Gastric Bypass & $1091(367)$ & $1375(590)$ & $<0.001$ \\
\hline Gastric sleeve & $1201(379)$ & $582(73)$ & $<0.001$ \\
\hline $\mathrm{HbA1c}(\%)$ & $5.50(1.00)$ & $5.17(0.70)$ & $<0.001$ \\
\hline
\end{tabular}


Table 2. The APOE groups (one-by-one) as predictors of the hormones adjusted for age, gender, BMI and point of time (before/after surgery) were analysed with linear mixed model. The q-values are Benjamini-Hochberg-adjusted $p$-values for 13 analyses between each APOE group and the hormones.

\begin{tabular}{|c|c|c|c|}
\hline Dependent Variable & $\begin{array}{c}\text { APOE E3 Compared } \\
\text { with E2 } \\
\text { B }(95 \% \text { CI }) \\
p \text {-Value/q-Value }\end{array}$ & $\begin{array}{c}\text { APOE E4 Compared } \\
\text { with E2 } \\
\text { B }(95 \% \mathrm{CI}) \\
p \text {-Value/q-Value }\end{array}$ & $\begin{array}{c}\text { APOE E4 Compared } \\
\text { with E3 } \\
\text { B }(95 \% \mathrm{CI}) \\
p \text {-Value/q-Value }\end{array}$ \\
\hline TSH (mIE/L) & $\begin{array}{c}0.42(-0.47 ; 1.31) \\
p=0.350 / \mathrm{q}=0.766\end{array}$ & $\begin{array}{c}0.48(-0.43 ; 1.40) \\
p=0.294 / q=0.713\end{array}$ & $\begin{array}{c}0.06(-0.51 ; 0.64) \\
p=0.825 / \mathrm{q}=0.894\end{array}$ \\
\hline Thyroxin (T4) (pmol/L) & $\begin{array}{l}-0.88(-3.56 ; 1.79) \\
p=0.511 / \mathrm{q}=0.766\end{array}$ & $\begin{array}{c}-0.68(-3.42 ; 2.07) \\
p=0.623 / \mathrm{q}=896\end{array}$ & $\begin{array}{c}0.21(-1.52 ; 1.93) \\
p=0.812 / \mathrm{q}=0.894\end{array}$ \\
\hline Free T3 (pmol/L) & $\begin{array}{c}0.21(-0.44 ; 0.85) \\
p=0.522 / \mathrm{q}=0.766\end{array}$ & $\begin{array}{l}-0.13(-0.79 ; 0.53) \\
p=0.688 / q=0.896\end{array}$ & $\begin{array}{l}-0.34(-0.75 ; 0.07) \\
p=0.104 / \mathrm{q}=0.451\end{array}$ \\
\hline Reverse T3 (pmol/L) & $\begin{array}{l}-0.02(-0.17 ; 0.13) \\
p=0.789 / \mathrm{q}=0.855\end{array}$ & $\begin{array}{c}0.01(-0.14 ; 0.17) \\
p=0.869 / q=0.938\end{array}$ & $\begin{array}{c}(-0.06 ; 0.13) \\
p=0.498 / \mathrm{q}=0.809\end{array}$ \\
\hline Parathyroid hormone (pmol/L) & $\begin{array}{c}0.49(-1.02 ; 2.01) \\
p=0.519 / \mathrm{q}=0.766\end{array}$ & $\begin{array}{c}0.45(-1.10 ; 2.01) \\
p=0.563 / q=0.896\end{array}$ & $\begin{array}{l}-0.04(-1.02 ; 0.94) \\
p=0.936 / \mathrm{q}=0.936\end{array}$ \\
\hline Cortisol (nmol/L) & $\begin{array}{l}-20.7(-86.5 ; 45.0) \\
p=0.530 / \mathrm{q}=0.766\end{array}$ & $\begin{array}{c}-56.0(-123.6 ; 11.5) \\
p=0.102 / \mathrm{q}=0.459\end{array}$ & $\begin{array}{l}-35.3(-77.6 ; 6.9) \\
p=0.100 / q=0.451\end{array}$ \\
\hline SHBG (nmol/L) & $\begin{array}{l}19.94(-6.06 ; 45.94) \\
p=0.130 / q=0.689\end{array}$ & $\begin{array}{l}21.94(-4.77 ; 48.64) \\
p=0.106 / \mathrm{q}=0.459\end{array}$ & $\begin{array}{l}2.00(-14.75 ; 18.76) \\
p=0.812 / \mathrm{q}=0.894\end{array}$ \\
\hline Testosterone (nmol/L) & $\begin{array}{c}0.48(-2.01 ; 2.97) \\
p=0.699 / \mathrm{q}=0.826\end{array}$ & $\begin{array}{l}-0.10(-2.66 ; 2.46) \\
p=0.938 / q=0.938\end{array}$ & $\begin{array}{l}-0.58(-2.19 ; 1.02) \\
p=0.469 / \mathrm{q}=0.809\end{array}$ \\
\hline Free testosterone index & $\begin{array}{c}0.01(-0.53 ; 0.54) \\
p=0.980 / \mathrm{q}=0.980\end{array}$ & $\begin{array}{l}-0.09(-0.64 ; 0.46) \\
p=0.758 / q=0.896\end{array}$ & $\begin{array}{l}-0.09(-0.44 ; 0.25) \\
p=0.596 / \mathrm{q}=0.861\end{array}$ \\
\hline Leptin (pmol/L) & $\begin{array}{c}-98(-483 ; 286) \\
p=0.610 / \mathrm{q}=0.793\end{array}$ & $\begin{array}{c}-248(-644 ; 147) \\
p=0.212 / q=0.689\end{array}$ & $\begin{array}{c}-150(-398 ; 97) \\
p=0.227 / \mathrm{q}=0.619\end{array}$ \\
\hline Adiponectin (mg/L) & $\begin{array}{c}3.02(-1.22 ; 7.27) \\
p=0.159 / \mathrm{q}=0.689\end{array}$ & $\begin{array}{c}4.66(0.29 ; 9.02) \\
p=0.037 / q=0.459\end{array}$ & $\begin{array}{c}1.63(-1.11 ; 4.37) \\
p=0.238 / q=0.619\end{array}$ \\
\hline Ghrelin $(\mathrm{pg} / \mathrm{mL})$ & $\begin{array}{c}176(-209 ; 562) \\
p=0.363 / \mathrm{q}=0.766\end{array}$ & $\begin{array}{c}73(-322 ; 469) \\
p=0.712 / q=0.896\end{array}$ & $\begin{array}{c}-103(-351 ; 145) \\
p=0.410 / \mathrm{q}=0.809\end{array}$ \\
\hline $\mathrm{HbA1c}$ & $\begin{array}{c}-0.87(-1.59 ;-0.15) \\
p=0.019 / \mathrm{q}=0.247\end{array}$ & $\begin{array}{l}-0.36(-1.10 ; 0.38) \\
p=0.329 / q=0.713\end{array}$ & $\begin{array}{c}0.51(0.04 ; 0.97) \\
p=0.034 / \mathrm{q}=0.442\end{array}$ \\
\hline
\end{tabular}

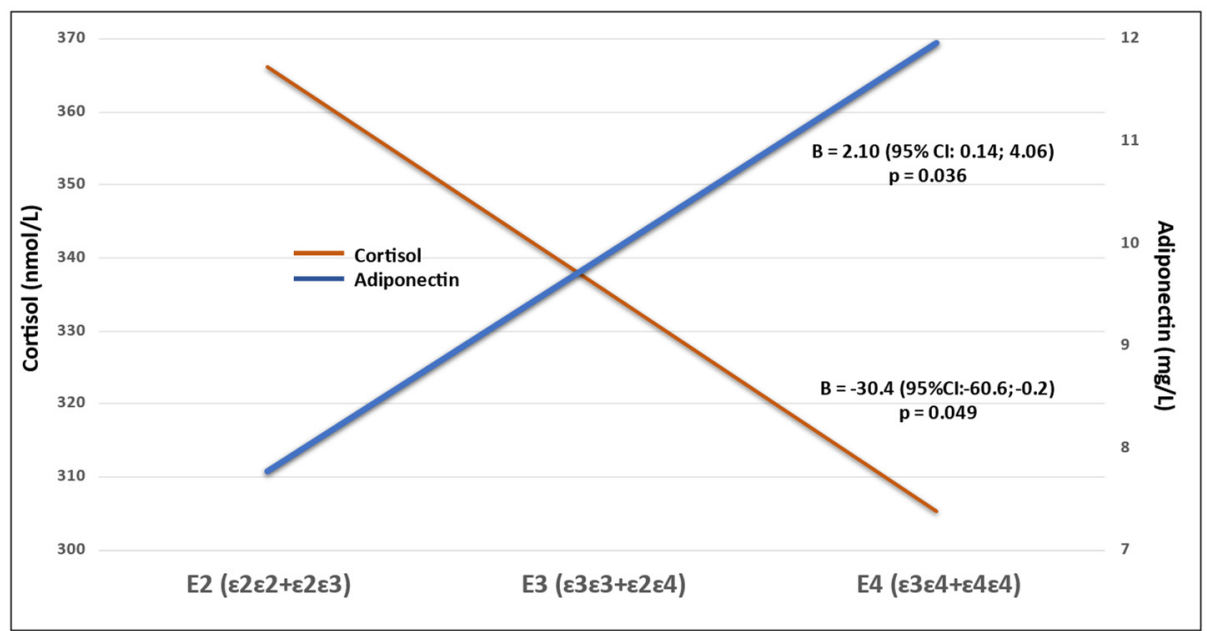

Figure 1. The associations between the ordered $A P O E$ groups and cortisol and adiponectin presented as the regression lines adjusted for the mean of age, gender, BMI and point of time. 
Table 3. Ordered APOE groups (E2-E3-E4) as a predictor of the hormones adjusted for age, gender, $\mathrm{BMI}$ and point of time (before/after surgery), analysed with linear mixed model. The q-values are Benjamini-Hochberg-adjusted $p$-values for 13 analyses between the APOE order and the hormones.

\begin{tabular}{|c|c|c|c|}
\hline Dependent Variable & $\begin{array}{c}\text { APOE Order } \\
\text { B (95\%CI) } \\
p \text {-Value/q-Value }\end{array}$ & Dependent Variable & $\begin{array}{c}\text { APOE Order } \\
\text { B (95\%CI) } \\
p \text {-Value/q-Value }\end{array}$ \\
\hline TSH (mIE/L) & $\begin{array}{c}0.18(-0.23 ; 0.59) \\
p=0.375 / q=0.813\end{array}$ & Testosterone (nmol/L) & $\begin{array}{l}-0.23(-1.38 ; 0.92) \\
p=0.695 / q=0.883\end{array}$ \\
\hline Thyroxin (T4) (pmol/L) & $\begin{array}{l}-0.16(-1.39 ; 1.07) \\
p=0.797 / \mathrm{q}=0.883\end{array}$ & Free testosterone index & $\begin{array}{l}-0.06(-0.31 ; 0.19) \\
p=0.634 / \mathrm{q}=0.883\end{array}$ \\
\hline Free T3 (pmol/L) & $\begin{array}{l}-0.16(-0.46 ; 0.14) \\
p=0.297 / \mathrm{q}=0.772\end{array}$ & Leptin (pmol/L) & $\begin{array}{c}-133(-310 ; 43) \\
p=0.136 / \mathrm{q}=0.589\end{array}$ \\
\hline Reverse T3 (pmol/L) & $\begin{array}{c}0.01(-0.05 ; 0.08) \\
p=0.664 / \mathrm{q}=0.883\end{array}$ & Adiponectin (mg/L) & $\begin{array}{c}2.10(0.14 ; 4.06) \\
p=0.036 / \mathrm{q}=0.319\end{array}$ \\
\hline Parathyroid hormone (pmol/L) & $\begin{array}{c}0.14(-0.56 ; 0.84) \\
p=0.694 / \mathrm{q}=0.883\end{array}$ & Ghrelin (pg/mL) & $\begin{array}{c}-9(-188 ; 170) \\
p=0.918 / \mathrm{q}=0.918\end{array}$ \\
\hline Cortisol (nmol/L) & $\begin{array}{c}-30.4(-60.6 ;-0.2) \\
p=0.049 / q=0.319\end{array}$ & HbA1c (\%) & $\begin{array}{c}0.02(-0.31 ; 0.40) \\
p=0.815 / \mathrm{q}=0.883\end{array}$ \\
\hline SHBG (nmol/L) & $\begin{array}{c}8.01(-4.06 ; 20.1) \\
p=0.189 / q=0.614\end{array}$ & & \\
\hline
\end{tabular}

\section{Discussion}

In our current study, the main findings include the positive and negative associations between the ordered APOE (E2-E3-E4) and adiponectin and cortisol, respectively. No significant associations were observed between the APOE alleles and the other hormones.

Adiponectin is a hormone that passes into the brain and has an appetite-regulating effect, increases energy expenditure and thermogenesis, potentiates the effect of leptin and reduces body weight [4,19]. Adiponectin values are low in subjects with obesity [4]. In healthy humans, adiponectin increases by overnutrition and weight gain [20]. Because adiponectin resistance rapidly occurs after fatty acid intake, the rise might be a compensatory response [21]. In subjects with obesity and insulin resistance, adiponectin does not respond to overfeeding, indicating adiponectin resistance $[4,21]$. The positive association between $\mathrm{E} 4$ and adiponectin in this study is in accordance with the protective effect of $\varepsilon 4$ against obesity [10].

In addition to the appetite-regulating effects, adiponectin is an indicator of insulin sensitivity. The positive association between $\mathrm{E} 4$ and adiponectin indicates a protective effect of $\varepsilon 4$ on diabetes, as reported in the meta-analysis by Lumsden et al. [10]. Our findings on adiponectin led to post hoc analyses of $\mathrm{HbA1c}$. The significantly higher $\mathrm{HbA1c}$ values in the E4 group compared with the E3 group is not as expected if $\varepsilon 4$ protects against diabetes, and is not as reported by Lumsden et al. [10]. HbA1c is a commonly used marker for the diagnosis and monitoring of treatment in diabetes. Without detailed knowledge of the treatment given to subjects with diabetes and the blood glucose levels of the subjects in the different groups, the $\mathrm{HbA} 1 \mathrm{c}$ results are unreliable as a marker of insulin sensitivity.

Adiponectin has also been associated with unfavourable effects, such as chronic heart failure, chronic kidney disease, cognitive impairment and Alzheimer's disease [22]. The discrepancy between the beneficial effects on glucose metabolism, inflammation and atherosclerosis, and no direct effect on the risk of type II diabetes and cardiovascular disease, and increased mortality across several diseases, has been mentioned as the adiponectin paradox [23].

Screening for endocrine disorders such as hypogonadism, polycystic ovary syndrome, Cushing's syndrome, thyroid dysfunction, diabetes, growth hormone deficiency and pseudohypoparathyroidism is mandatory in subjects with severe obesity [2,24]. In this study, 
cortisol was the only endocrine function associated with APOE polymorphism. High cortisol values are associated with overweight [25]. The negative association between the E4 group and cortisol seen in this study indicates that the protective effect of $\varepsilon 4$ against obesity could in part be related to corticosteroid metabolism. The meta-analysis by Lumsden et al. found no association between $A P O E$ polymorphism and disorders of the adrenal glands [10].

Glucocorticosteroids inhibit adiponectin secretion in animals, healthy persons and non-obese subjects with Cushing's syndrome [26]. The inhibitory effect could explain the negative association between adiponectin and cortisol in this study. Obesity has been reported to mask this effect, which seemed not to be the case in this study [26].

In accordance with other studies, no statistically significant associations of $A P O E$ polymorphism with thyroid and parathyroid disorders, sex hormones, and the adipokines ghrelin and leptin were observed [10]. In a previous study, we did not see any association between APOE polymorphism and body weight and weight loss after surgery [12]. In the same study, there was a fall in CRP after treatment; $\varepsilon 2$ and $\varepsilon 4$ were significantly associated with high and low CRP, respectively. The associations between APOE genotypes and endocrine functions could indicate that change in weight is a metabolic effect and not a direct $A P O E$ genotype effect.

\section{Strengths and Limitations}

The study population was an unselected and representative group of subjects referred for evaluation of bariatric surgery. The treatment followed national and international guidelines with a lifestyle intervention before surgery, which was performed with standard techniques, and regular follow-ups after surgery. A broad spectrum of hormones known to be related to obesity, or possibly related to obesity, was analysed. Information about the lipid profiles would have been desirable.

The unbalanced gender distribution in favour of females limits the external validity. All the analyses were adjusted for gender, and the limited number of participants made gender-specific analyses inappropriate. The results might represent female-specific effects.

There is no consensus about the grouping of the APOE variants, and this depends on the study population. Instead of having each individual genotype $\varepsilon 2 \varepsilon 2, \varepsilon 2 \varepsilon 3, \varepsilon 3 \varepsilon 3, \varepsilon 2 \varepsilon 4$, $\varepsilon 3 \varepsilon 4$ and e4 44 as separate groups, we decided to combine genotypes pairwise into three groups: E2 $(\varepsilon 2 \varepsilon 2+\varepsilon 2 \varepsilon 3)$, E3 $(\varepsilon 3 \varepsilon 3+\varepsilon 2 \varepsilon 4)$ and E4 $(\varepsilon 3 \varepsilon 4+\varepsilon 4 \varepsilon 4)$ to obtain larger groups whilst ensuring clear E2 and E4 profiles. A different grouping or leaving out the participant with $\varepsilon 2 \varepsilon 4$ could have given other results but has not been performed.

The explorative design with multiple testing increases the possibilities of type I errors. To reduce type I errors, $p$-values were adjusted for multiple testing. This strengthening of the methods, which removed all significant associations, demonstrates the uncertainty of the results. Similarly, because of the relatively small sample size, particularly in the $A P O E$ subgroups, negative results do not exclude an effect (type II error). Discrepancies between this and other studies could also be due to the study population (i.e., subjects with morbid obesity), different ethnic groups and the study design. The results could be specific for subjects with obesity. The lack of a reference group with healthy subjects is a limitation. Nevertheless, the results indicate endocrine effects of clinical importance of $A P O E$ polymorphism in subjects with morbid obesity. Confirmations from larger studies are desirable.

\section{Conclusions}

$A P O E$ polymorphism seems to have endocrine effects of clinical significance in subjects with morbid obesity. The $\varepsilon 4$ allele was positively and negatively associated with adiponectin and cortisol, respectively, indicating effects on metabolic functions and thus body weight. 
Author Contributions: Conceptualisation, P.G.F. and K.H.; methodology, P.G.F.; validation, P.G.F., A.J., K.H., J.O.A. and H.R.; formal analysis, P.G.F.; investigation, P.G.F., J.O.A. and H.R.; resources, P.G.F. and H.R.; data curation, P.G.F., A.J., J.O.A. and H.R.; writing-original draft preparation, P.G.F.; writing-review and editing, P.G.F., A.J., K.H., J.O.A. and H.R.; visualisation, P.G.F.; supervision, P.G.F.; project administration, P.G.F.; funding acquisition, P.G.F., J.O.A. and H.R. All authors have read and agreed to the published version of the manuscript.

Funding: The work was funded by an unrestricted grant from Innlandet Hospital Trust, Brumunddal, Norway; and Oslo University Hospital, Oslo, Norway.

Institutional Review Board Statement: The study was approved by the Norwegian Regional Committees for Medical and Health Research Ethics, PB 1130, Blindern, 0318 Oslo, Norway (reference number 2012/966 with an amendment of 28 June 2018). The study was conducted according to the Declaration of Helsinki. Institutional Review Board Statement was not mandatory when the study was approved by the Norwegian Regional Committees for Medical and Health Research Ethics, Oslo, Norway.

Informed Consent Statement: Informed consent was obtained from all subjects involved in the study.

Data Availability Statement: The raw datasets generated and analysed during the current study are not publicly available in order to protect participant confidentiality. Case report forms (CRFs) on paper are safely stored. The data were transferred deidentified to SPSS and R-studio for statistical analyses. The data files are stored by Innlandet Hospital Trust, Brumunddal, Norway, on a server dedicated to research. The security follows the rules given by the Norwegian Data Protection Authority, P.O. Box 8177 Dep. NO-0034 Oslo, Norway. The data are available on request to the authors.

Acknowledgments: The authors want to thank senior nursing officer Janne Dahlby Rostad at the obesity unit for tailoring the practical work to the research activities and study nurse Anja Byfuglien at Innlandet Hospital Trust for conscientious help with the practical work, and the Medical Laboratory Scientists at the Unit for Special Analyses, Department of Medical Biochemistry at Oslo University Hospital for APOE genotyping.

Conflicts of Interest: The authors declare no conflict of interest. The funders had no role in the design of the study; in the collection, analyses, or interpretation of data; in the writing of the manuscript, or in the decision to publish the results.

\section{References}

1. WHO. WHO: Obesity and Overweight. Available online: https://www.who.int/news-room/fact-sheets/detail/obesity-andoverweight (accessed on 13 September 2021).

2. Acosta, A.; Streett, S.; Kroh, M.D.; Cheskin, L.J.; Saunders, K.H.; Kurian, M.; Schofield, M.; Barlow, S.E.; Aronne, L. White Paper AGA: POWER-Practice Guide on Obesity and Weight Management, Education and Resources. Clin. Gastroenterol. Hepatol. 2017, 15, 631-649.e10. [CrossRef]

3. Yeung, A.Y.; Tadi, P. Physiology, Obesity Neurohormonal Appetite And Satiety Control. In StatPearls; StatPearls Publishing: Treasure Island, FL, USA, 2021.

4. Michalakis, K.G. Endocrine approach in the treatment of obesity: Is there any space for the adiponectin action? Endocr. Regul. 2020, 54, 157-159. [CrossRef]

5. Dornbush, S.; Aeddula, N.R. Physiology, Leptin. In StatPearls; StatPearls Publishing: Treasure Island, FL, USA, 2021.

6. Koliaki, C.; Liatis, S.; Dalamaga, M.; Kokkinos, A. The Implication of Gut Hormones in the Regulation of Energy Homeostasis and Their Role in the Pathophysiology of Obesity. Curr. Obes. Rep. 2020, 9, 255-271. [CrossRef]

7. Casimiro, I.; Sam, S.; Brady, M.J. Endocrine implications of bariatric surgery: A review on the intersection between incretins, bone, and sex hormones. Physiol. Rep. 2019, 7, e14111. [CrossRef]

8. Salas-Huetos, A.; Maghsoumi-Norouzabad, L.; James, E.R.; Carrell, D.T.; Aston, K.I.; Jenkins, T.G.; Becerra-Tomas, N.; Javid, A.Z.; Abed, R.; Torres, P.J.; et al. Male adiposity, sperm parameters and reproductive hormones: An updated systematic review and collaborative meta-analysis. Obes. Rev. 2021, 22, e13082. [CrossRef]

9. Chiurazzi, M.; Cozzolino, M.; Orsini, R.C.; Di Maro, M.; Di Minno, M.N.D.; Colantuoni, A. Impact of Genetic Variations and Epigenetic Mechanisms on the Risk of Obesity. Int. J. Mol. Sci. 2020, 21, 9035. [CrossRef]

10. Lumsden, A.L.; Mulugeta, A.; Zhou, A.; Hypponen, E. Apolipoprotein E (APOE) genotype-associated disease risks: A phenomewide, registry-based, case-control study utilising the UK Biobank. EBioMedicine 2020, 59, 102954. [CrossRef]

11. Kypreos, K.E.; Karavia, E.A.; Constantinou, C.; Hatziri, A.; Kalogeropoulou, C.; Xepapadaki, E.; Zvintzou, E. Apolipoprotein E in diet-induced obesity: A paradigm shift from conventional perception. J. Biomed. Res. 2017, 32, 183-190. [CrossRef] 
12. Farup, P.G.; Rootwelt, H.; Hestad, K. APOE-A genetic marker of comorbidity in subjects with morbid obesity. BMC Med Genet. 2020, 21, 146. [CrossRef]

13. Jansen, A.; Berg, J.P.; Klungsoyr, O.; Muller, M.H.B.; Lyche, J.L.; Aaseth, J.O. The Influence of Persistent Organic Pollutants on Thyroidal, Reproductive and Adrenal Hormones After Bariatric Surgery. Obes. Surg. 2020, 30, 1368-1378. [CrossRef]

14. Aasbrenn, M.; Lydersen, S.; Farup, P.G. A Conservative Weight Loss Intervention Relieves Bowel Symptoms in Morbidly Obese Subjects with Irritable Bowel Syndrome: A Prospective Cohort Study. J. Obes. 2018, 2018, 3732753. [CrossRef]

15. Schauer, P.R.; Ikramuddin, S.; Hamad, G.; Eid, G.M.; Mattar, S.; Cottam, D.; Ramanathan, R.; Gourash, W. Laparoscopic gastric bypass surgery: Current technique. J. Laparoendosc. Adv. Surg. Tech. A 2003, 13, 229-239. [CrossRef]

16. Roa, P.E.; Kaidar-Person, O.; Pinto, D.; Cho, M.; Szomstein, S.; Rosenthal, R.J. Laparoscopic sleeve gastrectomy as treatment for morbid obesity: Technique and short-term outcome. Obes. Surg. 2006, 16, 1323-1326. [CrossRef]

17. Han, S.; Xu, Y.; Gao, M.; Wang, Y.; Wang, J.; Liu, Y.; Wang, M.; Zhang, X. Serum apolipoprotein E concentration and polymorphism influence serum lipid levels in Chinese Shandong Han population. Medicine 2016, 95, e5639. [CrossRef]

18. Hestad, K.A.; Engedal, K.; Whist, J.E.; Farup, P.G. The effect of ApoE e4 on blood pressure in patients with and without depression. Neuropsychiatr. Dis. Treat. 2016, 12, 1365-1370. [CrossRef]

19. Qi, Y.; Takahashi, N.; Hileman, S.M.; Patel, H.R.; Berg, A.H.; Pajvani, U.B.; Scherer, P.E.; Ahima, R.S. Adiponectin acts in the brain to decrease body weight. Nat. Med. 2004, 10, 524-529. [CrossRef]

20. Heilbronn, L.K.; Campbell, L.V.; Xu, A.; Samocha-Bonet, D. Metabolically protective cytokines adiponectin and fibroblast growth factor-21 are increased by acute overfeeding in healthy humans. PLoS ONE 2013, 8, e78864. [CrossRef]

21. Engin, A. Adiponectin-Resistance in Obesity. Adv. Exp. Med. Biol. 2017, 960, 415-441. [CrossRef]

22. Waragai, M.; Ho, G.; Takamatsu, Y.; Wada, R.; Sugama, S.; Takenouchi, T.; Masliah, E.; Hashimoto, M. Adiponectin Paradox in Alzheimer's Disease; Relevance to Amyloidogenic Evolvability? Front. Endocrinol. 2020, 11, 108. [CrossRef]

23. Menzaghi, C.; Trischitta, V. The Adiponectin Paradox for All-Cause and Cardiovascular Mortality. Diabetes 2018, 67, 12-22. [CrossRef]

24. Seetho, I.W.; Wilding, J.P. How to approach endocrine assessment in severe obesity? Clin. Endocrinol. 2013, 79, 163-167. [CrossRef]

25. Hewagalamulage, S.D.; Lee, T.K.; Clarke, I.J.; Henry, B.A. Stress, cortisol, and obesity: A role for cortisol responsiveness in identifying individuals prone to obesity. Domest. Anim. Endocrinol. 2016, 56, S112-S120. [CrossRef]

26. Fallo, F.; Scarda, A.; Sonino, N.; Paoletta, A.; Boscaro, M.; Pagano, C.; Federspil, G.; Vettor, R. Effect of glucocorticoids on adiponectin: A study in healthy subjects and in Cushing's syndrome. Eur. J. Endocrinol. 2004, 150, 339-344. [CrossRef] 